07

\title{
Воздействие низкочастотного шумового сигнала на генератор одночастотных колебаний миллиметрового диапазона волн на лавинно-пролетном диоде
}

\author{
() В.Д. Котов, Е.А. Мясин ॠ
}

Институт радиотехники и электроники им. В.А. Котельникова РАН

(Фрязинский филиал)

"E-mail: eam168@ms.ire.rssi.ru

Поступило в Редакцию 26 апреля 2017 г.

Впервые получена генерация шумовых колебаний в одночастотном автогенераторе на лавинно-пролетном диоде $7 \mathrm{~mm}$ диапазона длин волн при воздействии низкочастотным узкополосным $(\sim 3 \mathrm{MHz})$ шумовым сигналом на цепь питания лавинно-пролетного диода.

DOI: 10.21883/PJTF.2017.22.45263.16835

Впервые возможность генерации хаотических колебаний с широким спектром мощности за счет нелинейного взаимодействия многих собственных частот многорезонансной автоколебательной системы была показана в автогенераторе из двух ламп бегущей волны, замкнутых в кольцо, в которой одна из ламп выполняла функцию нелинейного элемента, вторая - усилителя мощности [1-3]. К настоящему времени исследовано множество самых разнообразных автоколебательных систем, демонстрирующих хаотическую динамику как у нас в стране [4], так и за рубежом [5]. С развитием твердотельной СВЧ-электроники оказалось возможным создавать системы в микроволновом диапазоне с использованием, например, транзисторов даже с большей шириной спектра, чем в лампах бегущей волны [6-8]. Однако в миллиметровом диапазоне, который транзисторы только начинают „осваивать“, в твердотельных генераторах приходится использовать лавиннопролетные диоды (ЛПД) и диоды Ганна. При этом как для получения моногенерации в генераторе на основе ЛПД (ГЛПД), так и для получения генерации хаотических колебаний используют волноводно- 
коаксиальные камеры $[9,10]$, в последнем случае несколько изменив их конструкцию $[11,12]$. В настоящее время генераторы шума микроволнового и миллиметрового диапазона, использующие хаотическую динамику активных автоколебательных систем, востребованы для самых разнообразных областей науки и техники.

Исследовались и другие методы реализации режимов нелинейной хаотизации колебаний при генерации в ГЛПД. В работе [13] показана возможность хаотизации колебаний в генераторе гармонических колебаний сантиметрового диапазона длин волн за счет воздействия внешнего гармонического сигнала частотой $0.150 \mathrm{MHz}$ на цепь питания такого ГЛПД. В данном случае воздействие низкочастотного (НЧ) сигнала происходит непосредственно на электронный поток, который возбуждает высокочастотную (ВЧ) автоколебательную систему генератора. Однако в этом случае в нелинейном режиме работы ГЛПД генерирует узкополосный шумовой сигнал $~ 14 \mathrm{MHz}$ при неравномерности спектра $\sim 10 \mathrm{~dB}$.

Таким образом, генерацию ВЧ-шумового сигнала обеспечивает нелинейный режим взаимодействия НЧ-гармонического сигнала с генерируемым одночастотным ВЧ-сигналом через изменение параметров электронного потока. Но основная цель экспериментаторов - добиться нелинейной хаотизации колебаний, и тот факт, что это связано с изменением движения носителей в пространстве дрейфа ЛПД, остается без внимания.

В зарубежной литературе в открытом доступе о подобных работах не сообщается. В основном все работы - как теоретические, например [14], так и экспериментальные [15] — направлены на реализацию возможности уменьшения шумовой составляющей в ГЛПД. Однако в [15] используется тот же прием воздействия (синхронизации) на цепь смещения полупроводникового генератора ВЧ-диапазона одночастотным сигналом более низкой частоты, чем его частота генерации. Также теоретически и экспериментально рассматриваются режимы работы ЛПД как источника сверхширокополосного шума в 8 и $3 \mathrm{~mm}$ диапазоне волн с полосой шума $25-40$ и $53-75 \mathrm{GHz}$ соответственно [16], хорошо известные и реализованные еще в СССР [17], хотя и в сантиметровом диапазоне волн. Имеет место и реклама подобных генераторов шума различными фирмами.

Задача настоящей работы состоит в том, чтобы показать возможность управления характером генерации в ГЛПД даже миллиметрового

Письма в ЖТФ, 2017, том 43, вып. 22 
диапазона волн путем воздействия шумовым низкочастотным сигналом непосредственно на поток носителей, трансформируя ее в пространстве дрейфа ЛПД в генерацию хаотических колебаний. При этом воздействии происходит разрушение сгустка электронов, взаимодействующего с ВЧ-полем колебаний одной частоты, и ГЛПД превращается в генератор шума.

Теперь рассмотрим процесс генерации одночастотного сигнала в ГЛПД. Известно, что в ГЛПД имеет место зависимость частоты генерации от тока диода. Она перестраивается вверх при увеличении тока через диод. Поэтому любое, даже достаточно медленное, изменение тока ЛПД должно приводить к изменению частоты генератора. И чем больше амплитуда изменения тока через диод, тем шире должен быть диапазон изменения частоты. В связи с этим предлагается генерировать ВЧ-шумовой сигнал в ГЛПД за счет модуляции тока узкополосным НЧ-шумовым сигналом, т. е. воздействовать им на цепь питания ЛПД.

Именно такой способ и был использован для получения генерации шумового сигнала в ГЛПД $7 \mathrm{~mm}$ диапазона волн на ЛПД типа КА717Б для различных режимов его работы.

Хотя генераторная волноводно-коаксиальная камера ГЛПД была многорезонаторной и при больших токах могла обеспечивать генерацию широкополосных шумовых колебаний $[11,12]$, в ней имелась возможность производить перестройку резонаторов таким образом, чтобы имела место генерация только одной частоты при всех возможных изменениях тока через диод (от 32 до $80 \mathrm{~mA}$ ).

По мере увеличения тока происходила токовая перестройка частоты генерации, начиная с частоты $38.49 \mathrm{GHz}$ при токе $32 \mathrm{~mA}$ и кончая частотой $38.76 \mathrm{GHz}$ при токе $80 \mathrm{~mA}$.

Для проведения эксперимента по воздействию НЧ-шумового сигнала на цепь питания ГЛПД был создан источник низкочастотного шумового сигнала, спектр которого по уровню - $3 \mathrm{~dB}$ занимает полосу частот от нескольких $\mathrm{kHz}$ до $3 \mathrm{MHz}$ и около $10 \mathrm{MHz}$ по уровню $10 \mathrm{~dB}$.

Были также исследованы реализации процесса непосредственно на входе ввода питания в коаксиальную линию генераторной камеры с помощью осциллографа C1-75. Было установлено, что плотность распределения вероятности амплитуды напряжения $U$ подчиняется гауссову (нормальному) распределению с нулевым средним. Отклонение 

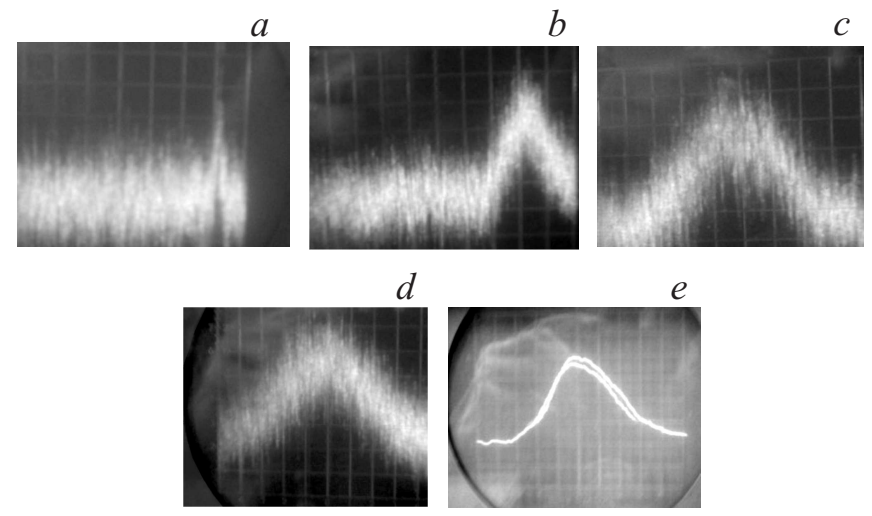

Рис. 1. Зависимость спектра ВЧ-сигнала от амплитуды НЧ-сигнала воздействия: $\sigma=0 ;(a), 0.05(b), 0.1(c)$ и $0.5 \mathrm{~V}(d, e)$.

$\sigma$ определялось по засветке экрана и служило оценкой амплитуды НЧ-шумового сигнала.

Результат воздействия этого НЧ-шумового сигнала для трех его уровней - при отсутствии отклонения или малом $(\sigma=0.05 \mathrm{~V})$, среднем $(\sigma=0.1 \mathrm{~V})$, максимальном $(\sigma=0.5, \mathrm{~V})$ отклонении на цепь питания ГЛПД представлен на фотографиях спектра высокочастотного сигнала $7 \mathrm{~mm}$ диапазона волн с экрана анализатора спектра C4-60 при токе через диод 80 и $32 \mathrm{~mA}$ на рис. 1 и 2 соответственно.

На рис. $1, a-d$ масштаб $20 \mathrm{MHz} / \mathrm{div}$, полоса видеофильтра $10 \mathrm{kHz}$, одна и та же скорость развертки $2 \mathrm{~ms} / \mathrm{div}$. На рис. $1, e$ представлена фотография того же сигнала, что и на рис. $1, d$, но полоса видеофильтра $100 \mathrm{~Hz}$, а масштаб $50 \mathrm{MHz} /$ div. Мощность на выходе генератора составляет $5.6 \mathrm{~mW}$ и практически не меняется при изменении уровня НЧ-шумового сигнала.

Как видно из рис. $1, a$, в режиме моногенерации при масштабе 20 $\mathrm{MHz} / \mathrm{div}$ ширина линии совпадает с шириной вертикальной линии масштабной сетки на экране C4-60, но уже при малом уровне внешнего сигнала она имеет ширину $\sim 20 \mathrm{MHz}$. По мере увеличения уровня сигнала ширина спектральной линии возрастает и при максимальном уровне воздействия, как видно на рис. $1, e$, достигает $\sim 170 \mathrm{MHz}$ по уровню $-3 \mathrm{~dB}$ и $\sim 250 \mathrm{MHz}$ по уровню $-6 \mathrm{~dB}$. При этом сохраняется

Письма в ЖТФ, 2017, том 43, вып. 22 

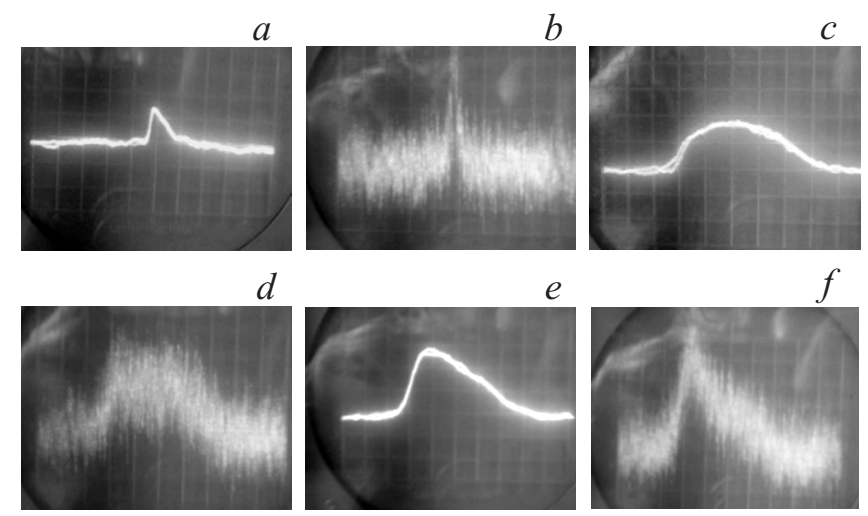

Рис. 2. Зависимость спектра ВЧ-сигнала от амплитуды НЧ-сигнала воздействия: $a, b-0 \mathrm{~V}(10 \mathrm{MHz} / \mathrm{div}), c, d-\sigma=0.1 \mathrm{~V}(20 \mathrm{MHz} / \mathrm{div}) ; e, f-\sigma=0.5 \mathrm{~V}$ (20 MHz/div).

шумовой характер сигнала с распределением вероятностей, близким к гауссову.

Такая же картина трансформации спектра ВЧ-сигнала наблюдалась при токе диода $50 \mathrm{~mA}$. При воздействии внешнего НЧ-шумового сигнала происходит превращение моногенерации в генерацию шумового сигнала с шириной спектра по уровню $-6 \mathrm{~dB} \sim 250 \mathrm{MHz}$. Таким образом, ширина спектра шума и в этом случае, как и в случае с рабочим током $80 \mathrm{~mA}$, оказывается равной диапазону токовой перестройки частоты ГЛПД.

Результат воздействия НЧ-шумовым сигналом на цепь питания ЛПД вблизи пускового режима при токе диода $32 \mathrm{~mA}$ в зависимости от уровня воздействия для двух значений полосы видеофильтра $(100 \mathrm{~Hz}$ и $10 \mathrm{kHz}$ ) попарно представлен на рис. 2.

Как видно из рис. 2, вблизи пускового режима генерации также происходит перевод ГЛПД в режим генерации шумового сигнала с распределением, близким к гауссову. Однако ширина спектра в этом случае значительно меньше и определяется только добротностью автоколебательной системы генератора.

Объяснение этому явлению может быть дано с помощью вольтамперной характеристики (BAX) ЛПД после пробоя. При достижении 
пускового режима моногенерации и дальнейшем увеличении тока на BAX располагается единственная рабочая точка с координатами $U-I$. Это означает, что в пространстве дрейфа диода из потока электронов, движущихся сначала хаотически, под действием ВЧ-поля сформировался сгусток электронов и движется в его тормозящей фазе, отдавая ВЧ-полю свою кинетическую энергию. Воздействие на цепь питания шумовым сигналом приводит к тому, что к данным значениям $U$ и $I$ добавляется шумовая составляющая, изменяющая по случайному закону ток диода. В результате величина постоянного тока, обеспечивающая его величину, необходимую для моногенерации, теперь оказывается „размазанной“ по некоторому диапазону амплитуд $\sigma$ тока, изменяющегося по случайному закону. Это приводит к разрушению сформированного сгустка электронов и подавлению генерации на одной частоте, а в зависимости от величины этого диапазона $\sigma$ приводит сначала (в пусковом режиме и вблизи него) к генерации узкополосного шумового сигнала, предельная ширина спектра которого определяется добротностью автоколебательной системы ГЛПД. По мере увеличения рабочего тока относительно пускового (без внешнего НЧ-шумового сигнала) до $I>I_{s t}$ происходит перестройка вверх частоты моногенерации от $f_{s t}$ до $f$, что связано с изменением оптимальной для генерации фазы ВЧ-поля. В этом случае увеличение уровня НЧ-шумового сигнала и, как следствие, диапазона изменения тока диода при достаточно большой его величине обеспечивает генерацию широкополосного шумового сигнала с шириной спектра $\Delta F=f-f_{s t}$ за счет появления носителей тока, соответствующих „пройденным“ величинам тока при отсутствии модуляции.

В заключение отметим, что, как и в случае нелинейной хаотизации колебаний, в случае модуляции узкополосным НЧ-шумовым сигналом по цепи питания ЛПД генерируемый ВЧ-сигнал является прямошумовым, так как реализуется за счет механизма усиления собственных шумов, связанного с пролетной неустойчивостью.

Фактически генератор переводится в режим регенеративного усиления собственных увеличенных шумов ЛПД.

Таким образом, предложен и продемонстрирован новый способ перевода одночастотной генерации ГЛПД миллиметрового диапазона с узкополосной автоколебательной системой в режим шумовой генерации, причем при слабой нелинейности ее активного полупроводникового элемента.

Письма в ЖТФ, 2017, том 43, вып. 22 


\section{Список литературы}

[1] Мясин Е.А., Кислов В.Я., Богданов Э.В. Способ генерирования электромагнитных шумовых колебаний. А.С. № 1125735. Опубл. 23.11.84. БЛ № 43 с приоритетом от 22.06.1967.

[2] Кислов В.Я., Залогин Н.Н., Мясин Е.А. // РЭ. Радиотехника и электроника. 1979. T. 24. № 6. C. 1118.

[3] Кислов В.Я., Мясин Е.А., Залогин Н.Н. // РЭ. 1980. Т. 25. № 10. С. 2160.

[4] Дмитриев Б.С., Жарков Ю.Д, Рыскин Н.М., Шигаев А.М. // РЭ. 2001. Т. 46. № 5. C. 604-610.

[5] Kennedy M.P. // IEEE Transac. Circuits Syst. I.: 1994. V. 41. Iss. 11. P. 771-774.

[6] Tamasevicius A., Bumeliene S., Lindberg E. // Electron. Lett. 2004. V. 40. P. $1569-1570$.

[7] Li J.X., Wang Y.C., Ma F.C. // Nonlinear Dyn. 2013. V. 72. P. 575-580.

[8] Максимов Н.А., Панас А.И. // Письма в ЖТФ. 2017. Т. 43. В. 3. С. 88-94.

[9] Misawa T., Kenyon N.D. // IEEE Trans. MTT. 1970. V. MTT-18. P. 969.

[10] Kenyon N.D. // G-MTT Symp. Digest. 1970. P. 300-303.

[11] Мясин Е.А., Котов В.Д. // Радиотехника. 2005. № 3. С 46-50.

[12] Мясин E.A., Котов В.Д. Генератор СВЧ шумовых колебаний. Патент № 2614925 РФ. Заявка № 2015154277 от 17.12. 2015. Опубл. 30.03.2017. Бюл. № 10 .

[13] Кокорин И.А. // Электронная техника. Сер. 1. 1984. В. 2. С. 25-27.

[14] Sjolund A. // Int. J. Electron. 1973. V. 34. N 4. P. 551-564.

[15] Okamoto H., Ikeda M. Injection-locked ultra-high frequency solid-state oscillator. Patent US 4099144 A. 26.04.1976. Publ. date 04.07.1978.

[16] Radmanesh M.M., Cadwallader J.M. // Microwave J. 1991. V. 34. N 4. P. 125133.

[17] Тагер А.С., Вальд-Перлов В.М. Лавинно-пролетные диоды и их применение в технике СВЧ. М.: Сов. радио, 1968. 480 с. 